\title{
O modernismo passadista de Ronald de Carvalho
}

\author{
The old-fashioned modernism of \\ Ronald de Carvalho
}

\author{
Dominichi Miranda de Sá \\ Pesquisadora da Casa de Oswaldo Cruz/Fiocruz \\ dominichi@coc.fiocruz.br
}

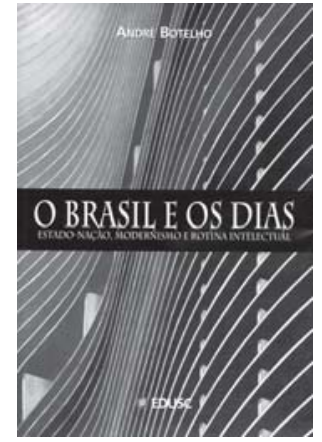

Botelho, André. O Brasil e os dias: Estado-nação, modernismo e rotina intelectual. Bauru: Edusc, 2005. 255p.
'T empo' é a categoria-chave desse belo trabalho do sociólogo André 1 Botelho, O Brasil e os dias: Estado-nação, modernismo e rotina intelectual. Trata-se de análise da obra de Ronald de Carvalho (1893-1935), diplomata e literato carioca com importante produção cultural como poeta e ensaísta nas décadas de 1920 e 1930.

Nos seis capítulos do livro, fruto da sua tese de doutorado em ciências sociais, defendida em 2002 na Unicamp, o autor detalha as idéias de Carvalho de modo a esclarecer que a sua poesia era a política, que o tema primordial de sua literatura era a construção do Estado-nação no Brasil e seu método, uma variação do exercício proustiano (p.197). Munida de concepção historicista da história e conservadorismo político, sua obra foi uma espécie de incursão no passado 'em busca do tempo perdido', mas, saliente-se, com função propositiva - a identificação de uma 'autêntica' realidade nacional, de modo a afiançar a formação de uma 'genuína' cultura brasileira e a organização social e política do país.

Ainda que a procura pela dita 'realidade nacional' não constituísse novidade, sendo mesmo pauta obrigatória entre homens de letras e homens de Estado do período, o especial arranjo entre obra e empenho na trajetória de Ronald de Carvalho exigia, segundo esse seu estudioso, a recuperação de seu 'esquecido' trabalho literário (p.15) e a rediscussão do epíteto que recebeu de 'poeta menor' do modernismo (p.29). Sim, foi poeta, mas por ter pretendido elaborar sua produção cultural como um meio de promoção de solidariedade social e de propaganda nacionalista, Carvalho foi, ainda segundo o autor de $\mathrm{O}$ Brasil e os dias, um importante 'intelectual'; ou seja, um intérprete do momento político do país e, exatamente por isso, um dos atores das transformações decorridas naquelas décadas. E, diga-se logo, essa afirmação é o ponto de partida do livro, a hipótese que leva seu autor a percorrer, em interessante diálogo, questões atinentes à sociologia do conhecimento e à história intelectual (sobretudo as que se referem às relações antes interdependentes que disjuntivas entre 'texto' e 'contexto'), e, assim, a analisar 'idéias' como "forças sociais reflexivas atuantes nos processos de mudança social em geral" (p.38).

Com refinados argumentos, André Botelho demonstra que refletir e agir sobre o 'tempo', de forma tanto a valorizar elementos da história nacional quanto a apressar a chegada do futuro, era o ponto principal 
da agenda desse literato, que, à semelhança de vários outros intelectuais da sua geração, ocupou-se em propor caminhos em direção à modernização do país. Visto, à época, como simultaneamente cosmopolita e provinciano, moderno e atrasado, liberal e oligárquico, o Brasil das primeiras décadas da República, por sua instabilidade político-social, parecia exigir de seus intelectuais propostas de recriação institucional e renovação cultural. A mudança do regime político, em um contexto imediatamente posterior ao fim da escravidão, impôs uma visão diferenciada da unidade nacional e das questões relacionadas à cidadania; donde a urgência na delimitação dos padrões de sua identidade (Carvalho, 1981, 1988, 1998, 1999; Mattos, 1987). A essa demanda acudiu Ronald de Carvalho com sua obra, entre outros letrados do período.

Assim narrado, o enredo desse livro poderia tão-somente se somar a várias outras análises da produção intelectual brasileira da passagem do século XIX para o XX, já que, à primeira vista, confirma sua abordagem, seu método, objeto e diagnóstico. Nos últimos anos, não foram poucos os autores a oferecer obras calcadas em fórmula que fez equivaler problema a conclusão; qual seja, 'intelectuais' teriam sido os intérpretes e os construtores da 'tardia' e 'periférica' identidade nacional. No entanto, para Botelho, longe de constituir um guia para a análise, o engajamento nacionalista dos intelectuais brasileiros, de 1910 a 1930, é questão intrincada e complexa, e a sua interpretação desse panorama, cuja detalhadíssima discussão teórica ocupa todo o primeiro capítulo do livro, é muito rica. Não é à toa a objetividade da pergunta com que inicia o seu texto: “O que Ronald de Carvalho estava fazendo ao escrever seus numerosos artigos, conferências e ensaios desde os últimos anos da década de 1910, por toda a década de 1920 e na primeira metade da década de 1930?" (p.15). E a persuasiva resposta que desdobra em sua análise não é o único mérito do livro.

Ressalto que, além da opção por 'desnaturalizar' a participação dos intelectuais no processo de formação da nação, recusando-se de pronto a percebê-la como uma espécie de vocação à criação cultural, ou como se origem familiar, boa formação educacional e acesso a diplomas os predestinassem à crítica social e política, André Botelho dedica-se a analisar um período histórico, em linhas gerais, bastante desvalorizado pelas ciências sociais, pela historiografia e pela crítica literária. Usualmente (in)definidas (e até bem recentemente) como de mera transição, ou, em termos cronológicos, como de gestação ou maturação de tendências intelectuais e experiências culturais vindouras, as duas primeiras décadas do século XX ganharam classificações bastante desabonadoras: 'pré-científicas', 'pré-modernas', 'ideológicas', 'beletristas', constituiriam, em suma, uma época cultural 'frívola' à espera de vanguardas intelectuais que confeririam, finalmente, autenticidade, disciplina e sistematicidade às idéias brasileiras. Ao contemplar o período por meio da obra de Ronald de Carvalho, o autor não só se opõe a essa interpretação amesquinhadora (perante a qual, é como se o período não tivesse especificidade, ou como se nele se produzissem traços que só fariam sentido no momento imediatamente posterior), como também se alinha a trabalhos que, nos últimos anos, vêm classificando as manifestações intelectuais dos primeiros tempos republi- 
canos, graças às suas demandas por novas formas de expressão e de comunicação com o público brasileiro, como 'modernistas' (Paes, 1985; Hardman, 1992; Lins, 1995; Araújo, 1994; Velloso, 1996; Gomes, 1999).

E além de fazer coro à crescente refutação da experiência paulista de 1922 como a precursora do modernismo no Brasil, o autor acentua o vigor transformador da produção intelectual realizada no Rio de Janeiro da época sem restringi-la à mera renovação estética. $\mathrm{O}$ teor político do modernismo, suas doses fortes de crítica ao liberalismo, seus diferentes matizes e perfis, inclusive o de recorte tradicionalista e conservador (como no caso de Carvalho), e sua expressiva representatividade no Estado durante o governo Vargas são importantíssimas facetas da produção intelectual brasileira do período que melhor se deixam entrever e compreender graças a essa análise da obra de Ronald de Carvalho. Destaco, quanto a este último ponto em particular, o item dedicado à atuação de Carvalho como diplomata e à discussão do Itamaraty como "um entreposto de idéias" (p.95-110).

Exame das idéias em seu tempo e 'em seu lugar', portanto, e construído por meio de excelente apropriação dos importantes estudos de Quentin Skinner $(1999,1988)$ de modo a levar às últimas conseqüências a sua perspectiva 'contextualista', sem, no entanto, reduzi-la à fórmula fácil, e mesmo equivocada, com que tem sido repetida à exaustão: 'idéias devem ser entendidas nos seus contextos'. Ainda que muito corrente, não é essa absolutamente a premissa skinneriana, e Botelho faz uso de princípios mais acertados do autor britânico: contextos não são meros cenários nos quais se desenrola a ação humana, espécie de pauta in actu para os homens históricos e garantia de inteligibilidade $a$ posteriori para os seus historiadores; são linguagens de época, repertórios mentais com seus vocabulários, metáforas, noções, regras, padrões analíticos, argumentos, conceitos, esquemas explicativos, estilos discursivos e topoi específicos. Não se trata, pois, de uma abordagem hiper-sociologizante das idéias, mas de compreender o passado como uma 'língua estrangeira', para recorrer à feliz e ilustrativa expressão cunhada por Peter Burke e Roy Porter para definir a obra skinneriana (Burke; Porter, 1993, p.13).

A seguir o Skinner de Botelho, deve-se estabelecer as articulações entre limites e liberdade de pensamento, ou entre as convenções de pensamento de uma dada época, os cânones de produção intelectual disponíveis, de um lado, e as possibilidades de criação cultural, de outro. Essa postura permite, no mesmo movimento, examinar tanto a incorporação por parte dos intelectuais, dos valores da sua cultura, do seu grupo social e da sua atividade profissional, quanto as novidades e inversões que propõem nesses mesmos campos sociais, culturais e profissionais. Essa premissa metodológica implica 'recolocar' as produções intelectuais do passado nos seus próprios termos e com imediato efeito epistemológico: apreender a historicidade dos significados das idéias de modo a avaliar seus ineditismo e diversidade, ou, melhor ainda, de forma a qualificar se o sentido proposto nos textos se adapta aos significados correntes em determinada época ou foge a eles. É nesse sentido que argumentos, enunciados e idéias intelectuais são entendidos como 'atos'; produzir criticamente significa intervir na ordem do 
mundo. Em outras palavras, produções intelectuais têm, invariavelmente, valor de ação por reinterpretarem, confirmarem ou negarem um dado status quo ou herança cultural.

Esse modelo baseado, como se vê, na investigação de tradições intelectuais e de linguagens como 'estilos de pensamento', é especialmente decisivo para a história e para a sociologia dos intelectuais por sua ênfase não só na produção, mas também na distribuição e no 'consumo' de idéias em diferentes épocas históricas, e André Botelho tira dele o melhor proveito. É nesse desenho, exatamente, que a obra de Ronald de Carvalho ganha especial relevo: ao salientar-se a sua reapropriação criativa de variadas chaves de leitura da cultura brasileira - de Sílvio Romero (e sua forte crítica à importação de 'idéias estrangeiras' e a ênfase no conhecimento da 'realidade nacional' por meio da abordagem historicista), bem como de Alberto Torres (e sua proposta de 'soluções brasileiras' para 'problemas brasileiros'), a Oliveira Vianna (em sua defesa das elites como as portadoras de 'vocação hegemônica', p.192). É por isso que, para Botelho, importante mesmo é o uso conseqüente que Ronald de Carvalho fez de diferentes leituras do Brasil. Nesse enquadramento, invalidam-se debates, por inúteis, sobre 'fontes', 'predecessores' 'influência', originalidade autoral ou coerência teórica.

Sendo assim, Carvalho foi poeta, diplomata, intelectual, um autêntico modernista, sem veios futuristas e sem arroubos de ruptura brusca com o passado nacional, mas com fortes traços conservadores e tradicionalistas. Foi também um simbolista, logo não apostava no valor denotativo da linguagem, mas era contrário à ornamentação do discurso, ainda que fizesse uso intenso da palavra como instrumento pedagógico e como meio de propaganda nacionalista. Não à toa ter sido reconhecido, mesmo à época, por sua importância como conferencista e publicista das 'coisas brasileiras'.

Tamanha "prontidão intelectual" (p.41), nas palavras do seu analista, para a crítica social e para a transmissão cultural, revela que a trajetória de Carvalho era expressão de programa necessariamente bifronte - cultural e político. Nessa perspectiva e assim irmanadas na interpretação proposta por André Botelho, 'idéias' e 'ação política' não constituem soma que signifique idiossincrasia de período histórico em crise, carente de definição, ou deficiência de obra menor, mas 'rotina' das produções intelectuais em geral; logo, também da obra de Ronald de Carvalho.

Para concluir, o único senão que encontro no trabalho são algumas de suas notas, excessivamente detalhadas e longas, cansativas, às vezes, justificáveis em uma tese acadêmica, mas absolutamente dispensáveis em livro destinado ao grande público. No entanto, tal como no conto de Borges, mapas nunca são, felizmente, um duplo fidedigno dos territórios que representam. Sendo assim, os pontos ressaltados nesta resenha não passam de roteiro incompleto de todas as importantes reflexões que os estudiosos e interessados em sociologia e história intelectual, mas também em pensamento social brasileiro e crítica literária, encontrarão certamente em $O$ Brasil e os dias. 


\section{REFERÊNCIAS BIBLIOGRÁFICAS}

Araújo, Ricardo

Benzaquem de

1994

Burke, Peter;

Porter, Roy (Org.) 1993

Carvalho, José Murilo de 1999

Carvalho, José Murilo de 1998

Carvalho, José Murilo de 1988

Carvalho, José Murilo de 1981

Gomes, Ângela

de Castro

1999

Hardman, Francisco F. 1992

Lins, Vera 1995

Mattos, Ilmar R. de 1987

Paes, José Paulo

1985

Skinner, Quentin 1999

Skinner, Quentin 1988

Velloso, Mônica P. 1996
Guerra e paz: Casa-Grande e Senzala e a obra de Gilberto Freyre nos anos 30. Rio de Janeiro: Ed. 34.

Linguagem, indivíduo e sociedade.

São Paulo: Unesp.

Brasil: nações imaginadas. In Carvalho, José Murilo de. Pontos e bordados: escritos de história e política. Belo Horizonte: Ed. UFMG.

A formação das almas: o imaginário da República no Brasil.

5. ed. São Paulo: Companhia das Letras.

Teatro das sombras: a política imperial.

São Paulo: Vértice.

A construção da ordem: a elite política imperial.

Brasília: Ed. UnB.

Essa gente do Rio...: modernismo e nacionalismo.

Rio de Janeiro: Fundação Getúlio Vargas.

Antigos modernistas. In: Novaes, Adauto (Org.). Tempo e história. São Paulo: Companhia das Letras.

Nos rastros de um modernismo carioca. Papéis Avulsos, Rio de Janeiro, n.47.

O tempo Saquarema.

São Paulo: Hucitec.

Gregos e baianos.

São Paulo: Brasiliense.

As fundações do pensamento político moderno.

São Paulo: Ed. da Unesp.

Meaning and understanding in the history of ideas. In: Tully, J.

(Ed.). Meaning and context: Quentin Skinner and his critics. Princeton: Princeton University Press. p.29-67.

Modernismo no Rio de Janeiro.

Rio de Janeiro: Fundação Getúlio Vargas. 